\author{
SERIES 'THE PLEURA' \\ Edited by H. Hamm and R.W. Light \\ Number 8 in this Series
}

\title{
Pleurodesis: state of the art
}

\author{
F. Rodriguez-Panadero*, V.B. Antony**
}

\begin{abstract}
Pleurodesis: state of the art. F. Rodriguez-Panadero, V.B. Antony. (CERS Journals 1997. ABSTRACT: Pleurodesis aims to achieve a symphysis between parietal and visceral pleural surfaces, in order to prevent accumulation of fluid or air in the pleural space. Its major indications are malignant effusions and pneumothorax, and a reexpandable lung is essential for the success of the technique. Moreover, expectation of a reasonably long survival is important before attempting pleurodesis.

A successful lung re-expansion is unlikely if the pleural pressure falls more than 20 $\mathrm{cmH}_{2} \mathrm{O} \cdot \mathrm{L}^{-1}$ of fluid removed, because there is a central bronchial obstruction or the lung is trapped by tumour and/or fibrin. Pleural fluid $\mathrm{pH}(<7.20)$ is a good indicator of the presence of trapped lung; moreover, a successful pleurodesis is less likely when $\mathrm{pH}$ is low, and this parameter is also a good predictor for survival of the patients.

Among the many sclerosing agents that have been used for pleurodesis, talc has achieved the best results, with an average success rate of approximately $90 \%$. The cellular and biochemical mechanisms involved in pleurodesis may be specific to the agent used, however, they may all follow a common final pathway leading to activation of the pleural coagulation cascade, the appearance of fibrin networks, and the proliferation of fibroblasts. The details of these mechanisms are still unclear and need to be further elaborated.
\end{abstract}

Eur Respir J 1997; 10: 1648-1654.
*Pulmonary Dept, Hospital Universitario Virgen del Rocio, Sevilla, Spain. **Division of Pulmonary and Critical Care, VAMC, Indiana University School of Medicine, Indianapolis, USA.

Correspondence: F. Rodriguez-Panadero El Mirador, P.13- $1^{\circ} \mathrm{B}$

E-41940 Tomares

Sevilla

Spain

Keywords: Malignant pleural effusions pleura

pleurodesis

pneumothorax

talc

Received: May 291996

Accepted after revision September 171996
The aim of pleurodesis is to achieve a symphysis between visceral and parietal pleural layers, in order to prevent accumulation of either air or fluid in the pleural space. Its main indications are malignant pleural effusions and pneumothorax. The choice of the right technique, sclerosing agent to be applied, criteria for selection of patients and evaluation of results are important and controversial issues. Furthermore, there is little information about the mechanisms that lead to pleural symphysis or the factors that influence the outcome of pleurodesis.

\section{Pleurodesis in malignant effusions}

Recurrent effusions of malignant origin are by far the most common indication for pleurodesis in clinical practice. This is because there is a lack of effective antitumoral treatment at later stages of the disease, and because palliative measures are necessary to improve symptoms related to the pleural effusion. Repeated thoracenteses are not usually suitable, since they may be troublesome to the patient and provoke important protein loss (about 40 $\mathrm{g} \cdot \mathrm{L}^{-1}$ of pleural fluid that is withdrawn), with infection of the pleural space as an added risk.

There are several points that should be addressed before attempting pleurodesis in malignant pleural effusions.
Are the symptoms (especially dyspnoea) directly related to the effusion?

It is mandatory to have an affirmative response to this question. Thoracentesis should relieve the patient's symptoms of dyspnoea, and pleurodesis is not likely to help those whose symptoms persist in spite of therapeutic thoracentesis. In some cases, dyspnoea is due to lung parenchymal involvement, even if this is not clearly detectable through image techniques, rather than to the pleural effusion itself. Pleural malignant involvement frequently occurs as a tertiary seeding from the lung parenchyma, even in cases of tumours of extrathoracic origin (fig. 1) [1, 2].

\section{Is the effusion recurrent?}

This is commonly thought to be an important issue for consideration of pleurodesis. However, recurrence will occur sooner or later in most of the patients with a proven malignant effusion. Furthermore, successful pleurodesis is less likely if the pleural malignancy is advanced. Therefore, some clinicians advocate that pleurodesis be attempted sooner rather than later during the course of the disease $[3,4]$. We currently agree with this position,

Previous articles in this series: No. 1: G. Miserocchi. Physiology and pathophysiology of pleural fluid turnover. Eur Respir J 1997; $10: 219-225$. No. 2: R.W. Light. Diagnostic principles in pleural disease. Eur Respir J 1997; 10: 476-481. No. 3: G.T. Kinasewitz. Transudative effusions. Eur Respir J 1997; 10: 714-718. No. 4: J. Ferrer. Pleural tuberculosis. Eur Respir J 1997; 10: 942-947. No. 5: H. Hamm, R.W. Light. Parapneumonic effusion and empyema. Eur Respir J 1997; 10: 1150-1156. No. 6: G. Hillerdal. Chylothorax and pseudochylothorax. Eur Respir J 1997; 10: 1157-1162. No. 7: F.M.N.H. Schramel, P.E. Postmus, R.G.J.R.A. Vanderschueren. Current aspects of spontaneous pneumothorax. Eur Respir J 1997; 10: 1372-1379. 
a)
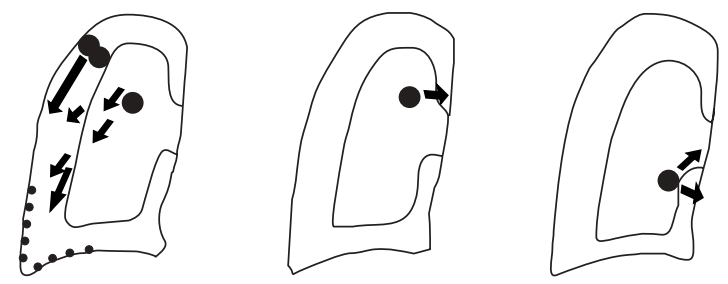

Dissemination* Superior vena cava Pericardium

b)

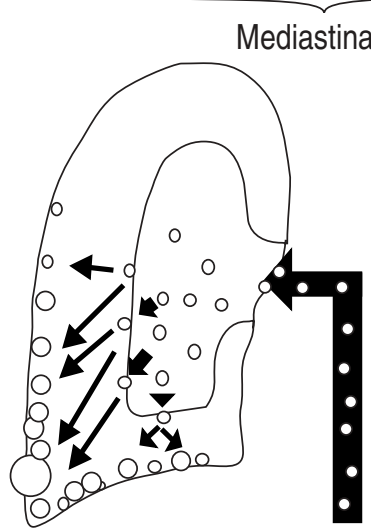

Fig. 1. - Mechanisms of neoplastic pleural tumour involvement in lung cancer and extrathoracic tumours. a) In lung cancer, the pleura can be reached through tumoral embolization from the primary tumour, or through direct invasion of the mediastinal pleura. *: secondary spreading to the pacietal pleural from the implants in the visceral pleura. b) Metastatic pleural spreading in extrathoracic tumours. (Drawn from [2]).

in order to avoid attempting pleural symphysis when the effusion is rapidly recurrent and the general condition of the patient has deteriorated.

\section{Is the lung re-expandable?}

It is important to demonstrate the ability to oppose the visceral and parietal pleura prior to attempting pleurodesis. The presence of a trapped lung should be suspected by the finding of very low pleural pressures as fluid is withdrawn during thoracentesis [5]. Thus, lung reexpansion is unlikely to be achieved easily if the pleural pressure falls more than $20 \mathrm{cmH}_{2} \mathrm{O} \cdot \mathrm{L}^{-1}$ of fluid removed. Extremely low pleural pressures after thoracentesis (even less than $-50 \mathrm{cmH}_{2} \mathrm{O}$ ) can be due either to a lung trapped by fibrin or tumour, or to a central tumour occluding the main ipsilateral bronchus. However, under these circumstances, thoracentesis can be dangerous because of rapid changes in intrathoracic pressures. Instead, it is recommended that measurement of pleural fluid $\mathrm{pH}$ be used as a first approach to assess multiple factors in evaluating a patient prior to pleurodesis.

In a study performed on 180 patients with malignant pleural effusion, who were submitted to thoracoscopy and talc pleurodesis, we found that trapped lung was present in $36 \%$ of the patients with pleural fluid $\mathrm{pH}<7.20$, as opposed to $9 \%$ in those with higher $\mathrm{pH}$ levels $(\mathrm{p}<0.001)$ [6]. However, a good pleural symphysis was obtained in as many as 11 of the 16 patients with trapped lung (69\%). In another study, successful pleurodesis was obtained in $90 \%$ of the patients with $\mathrm{pH}>7.30$, in only $33 \%$ when $\mathrm{pH}$ was $<7.20$, and in none of the patients with $\mathrm{pH}<7.15$, regardless of the presence or absence of a trapped lung [7]. Thus, $\mathrm{pH}$ levels had a surprisingly greater discrimi- nant power to predict the outcome of pleurodesis than trapped lung itself, as observed during thoracoscopic exploration. These results suggest that, besides mechanical factors, there must be other biological implications in low $\mathrm{pH}$ patients that account for the outcome of pleurodesis. Based on these and other findings (see section on "Biological aspects of pleurodesis"), it is currently believed that certain characteristics of the neoplastic lesions in the pleura play a role, as important as the tumour burden, regarding the outcome of pleurodesis.

When complete lung re-expansion is not possible or pleurodesis fails, palliation of symptoms due to the pleural effusion can be obtained with other alternative options, such as pleuroperitoneal shunting or pleurectomy. PETROU et al. [8] inserted a pleuroperitoneal shunt in 63 patients with "trapped lung syndrome", and obtained relief of symptoms in more than $90 \%$ of patients. However, the shunt became blocked in $12 \%$ of the cases, and had, therefore, to be either removed or replaced several weeks after its insertion. Thoracotomy with pleurectomy can sometimes be a valid alternative, but it has significant morbidity and mortality, and needs to be applied to patients in good physical condition and with a reasonably long expected survival [9]. Video-assisted thoracoscopic pleurectomy has gained acceptance in recent years, and has achieved good results in selected patients, especially those with mesothelioma [10].

\section{What is the life expectancy?}

Obviously, aggressive techniques, such as pleurodesis, should not be attempted in patients whose expected survival is short. Certain clinical parameters (e.g. Karnofsky index) can be of help in making decisions. In our experience, pleural fluid glucose and $\mathrm{pH}$ determinations are very useful in selecting patients as candidates for pleurodesis. In 125 patients with metastatic pleural carcino$\mathrm{ma}$, those who presented with a $\mathrm{pH}<7.20$ and glucose $<60 \mathrm{mg} \cdot \mathrm{dL}^{-1}$ had a very short life expectancy $(1.9 \mathrm{mon}-$ ths on average). A more conservative approach should, therefore, be considered in such patients [11]. The strong correlation found between glucose and $\mathrm{pH}$ values and survival is also found in the relationship between $\mathrm{pH}$ and tumour lesions [12]; thus, the lower the value of $\mathrm{pH}$ the bigger the tumour burden in the pleural space. Based on these results and those from SAHN and Good [13], pleurodesis is not recommended in patients with low pleural fluid glucose and $\mathrm{pH}$ levels. Other alternative measures, such as repeated thoracenteses or the measures mentioned above, may be used for palliation of symptoms.

\section{Pleurodesis in benign conditions}

Although malignant pleural effusions are the most common indication for pleurodesis, there are other instances in which this technique may be indicated. Among these, the most frequent benign condition requiring pleural symphysis is pneumothorax. Benign, recurrent pleural effusion can also be an indication for pleurodesis in some selected cases.

\section{Pleurodesis in pneumothorax}

When dealing with a spontaneous pneumothorax, there are several issues involved that have a significant influence 
on the approach to treatment: 1) the relatively high incidence of spontaneous pneumothorax in young patients makes it mandatory to use techniques for pleurodesis that are both reliable and that would allow for a thoracotomy in the future, if necessary (i.e., resection of lung cancer, lung transplantation, etc.). 2) the rupture of bullae or blebs requires specific intervention besides pleurodesis, in order to prevent recurrence; and 3) the largely normal pleural mesothelial surface in pneumothorax patients leads to significantly greater pleural responsiveness, making it necessary to use higher doses of analgesics. Moreover, a lower dosage of the sclerosing agent should be used to obtain an adequate response from the pleural mesothelium.

In addition to the above considerations, there are two particular circumstances that require a special approach, i.e. the pneumothorax occurring in patients with acquired immune deficiency syndrome (AIDS) and in those with cystic fibrosis.

The primary goal in the treatment of pneumothorax is to achieve complete lung re-expansion, which is usually accomplished with pleural drainage, and underwater seal in most cases. Evacuation of air from the pleural space can be achieved with a small-bore drainage coupled to a Heimlich-type valve in others [14-17]. However, the rate of recurrence of pneumothorax is unacceptably high when drainage alone is used, and it is, therefore, advisable to use any technique that is suitable to achieve a pleural symphysis. In a prospective randomized study, ALMIND et al. [18] compared the recurrence of pneumothorax using drainage alone and drainage plus tetracycline or talc, and found a rate of 36,13 and $8 \%$, respectively, after an average follow-up of 4.6 yrs. Furthermore, AlFAGEME et al. [19] had a 9\% recurrence with tetracycline pleurodesis, as compared to $35 \%$ in patients with drainage alone.

In recent years, there has been a growing tendency to treat patients with pneumothorax using video-assisted thoracoscopic surgery (VATS), in order to achieve a resection of the bullae or blebs and achieve pleurodesis, either through local abrasion of the parietal pleura or localized apical pleurodesis [20-22]. However, this procedure is expensive, requires general anaesthesia and (usually) double-lumen tracheal intubation. Also, the rate of recurrence varies greatly, depending on identification and subsequent ablation of blebs, according to NAUNHEIM et al. [23].

The use of VATS or conventional thoracoscopy and pleurodesis, or thoracotomy, is dependent upon several variable factors [24-27], and there is no clear technique of choice so far. In young patients with recurrent pneumothorax, VATS would be recommendable, always combined with some technique aimed to induce pleural symphysis (usually mechanical pleural abrasion, or apical talc pleurodesis). Talc should not be used generously for achieving pleurodesis in pneumothorax in young patients, because the symphysis induced could make it impossible or exceedingly risky for the patient to undergo an open thoracotomy in the future [28]. On the other hand, conventional thoracoscopic talc pleurodesis can be used in elderly patients with spontaneous pneumothorax, which is frequently secondary to emphysematous lesions. These patients may not tolerate VATS because of the need for single-lung ventilation, and talc may be the sclerosing agent of choice $[18,27,29,30]$.
In pneumothorax, careful analgesia and titration of dosage of the sclerosing agent must be performed, as pointed out above, because the procedure may be much more painful than when treating malignant effusions. The talc dose for pneumothorax should not exceed 3-4 g (about 5-6 $\mu \mathrm{L}$ of dry talcum powder).

\section{Pneumothorax in patients with AIDS}

Spontaneous pneumothorax occurs rather frequently in patients with AIDS and Pneumocystis carinii infection. According to Metersky et al. [31] and Wait and Nogare [32] a history of cigarette smoking, aerosolized pentamidine treatment and the observation of pneumatoceles on chest films are associated with an increased risk, and chemical pleurodesis is, therefore, often indicated. KIMMEL et al. [33] have reported a technical modality of talc poudrage after bleb resection using VATS, so that even distribution of talc can be visually controlled. Conventional thoracoscopic talc poudrage can also be performed, and talc might even be instilled through the chest drainage without thoracoscopy (as we have done successfully in a few patients).

A specially developed disposable spray canister is now available for talc pleurodesis [34], and can be used through a single-entry thoracoscopy or through a chest tube. However, its use is much more expensive than plain sterile talc preparations. A single canister is usually sufficient for pneumothorax, but not for treatment of recurrent malignant effusions, which may have a late relapse after an initial success. Unfortunately, the two drawbacks that we have found in this device are that the delivery catheter may accidentally detach from the nozzle as pressure is applied, and that the cold temperature generated by the suddenly decompressed talc provokes more discomfort than standard talc sprayed in the usual way.

\section{Pneumothorax in patients with cystic fibrosis}

These patients require special management, since they have a tendency to develop repeated and bilateral pneumothoraces, but can be candidates for lung transplantation as well. Therefore, they need a treatment that is both efficient and yet will allow for future thoracotomy. A chest drainage with underwater sealing and/or mild suction would be the choice for a few days, and subsequent VATS with bullectomy and apical pleurodesis should be performed afterwards if the air leak persists. Despite concerns about the use of talc in young patients, there are some authors who advocate applying localized apical talc pleurodesis through thoracoscopy in such patients, especially if a previous pleurodesis attempt has failed [35].

\section{Pleurodesis in benign pleural effusions}

Although the main indication for pleurodesis in effusions is diffuse pleural malignancy, there are a few circumstances in which pleural symphysis may be indicated in the absence of pleural neoplasm. According to SUDDUTH and SAHN [36], the following three criteria must be met: 1) the effusion must be symptomatic; 2) the presence of a trapped lung should be excluded; and 
3) pleurodesis should be reserved for those cases where there is no other therapeutic alternative, or when this has already failed.

These three circumstances can be present in some cases of pleural effusions that are associated with cardiac failure, cirrhosis of the liver, nephrotic syndrome, chylothorax, or systemic lupus erythematosus. VARGAS et al. [37] have reported their experience using low dose ( $2 \mathrm{~g})$ talc in such conditions, with a very good rate of success. It must be emphasized that the same precautions as mentioned above for pneumothorax should be applied in benign effusion regarding chemical pleurodesis, as the pleural surface is often well-preserved.

It should be acknowledged that this is a limited indication for pleurodesis, and that it should be performed after a complete thoracoscopic exploration of the pleural cavity. From our own experience, we would give some supplementary recommendations to those quoted by SUDDUTH and SAHN [36]. Firstly, talc pleurodesis in effusions of cardiac origin is usually successful, provided that standard medical treatment is not forgotten. Secondly, pleural effusions associated with cirrhosis of the liver are very difficult to manage, since there are usually communications between the abdominal and pleural cavity, which can sometimes be seen during thoracoscopy. Therefore, if ascites cannot be controlled, pleurodesis will most likely be unsuccessful. CANTO et al. [38] reported an $86 \%$ rate of successful pleurodesis when ascites was absent, as opposed to $40 \%$ when it was present, even if the pleurodesis procedure was performed immediately following evacuation of the ascites.

Thirdly, in our experience, pleural effusion associated with nephrotic syndrome has a markedly increased risk of re-expansion pulmonary oedema when applying suction through the chest tube following pleurodesis, due to the usually severe hypoproteinaemia, and to the increased leak of proteins into the pleural space after an irritant agent has been instilled. Finally, successful pleurodesis in chylothorax requires that chyle flux through the thoracic duct be reduced to a minimum, using a special diet or intravenous hyperalimentation.

\section{Technical aspects of pleurodesis}

In order to achieve a complete pleural symphysis, several conditions need to be met, and they can be classified into mechanical and biological aspects.

\section{Mechanical aspects of pleurodesis}

Obviously, the complete removal of air or liquid from the pleural space is needed to keep the visceral and parietal pleural layers in close contact, allowing for the establishment of a tight symphysis. These goals are obtained with application of suction through appropriate drainage, provided that a trapped lung is ruled out (as explained above). To prevent obstruction by clots, the chest tube should be large enough (we usually insert a 28 French). It is extremely important that careful progressive suction be applied following instillation of the sclerosant, in order to prevent re-expansion pulmonary oedema.

When inducing pleurodesis in malignant pleural effusions, we initially leave the chest tube on underwater seal alone for about $3 \mathrm{~h}$ following thoracoscopic talc poudrage; then slowly apply progressive suction, beginning with $2-5 \mathrm{cmH}_{2} \mathrm{O}$, and doubling this rate every $3 \mathrm{~h}$, until a final negative pressure of about $20 \mathrm{cmH}_{2} \mathrm{O}$ is reached in the system. This final suction is maintained until less than $100 \mathrm{~mL}$ of fluid. $24 \mathrm{~h}^{-1}$ is drained. Usually the chest tube can be removed after 2-3 days [39]. In our experience, the first $3 \mathrm{~h}$ of suction are the most critical period, during which complications can occur and patient discomfort may be high. When air leak is observed (which may occur even with no lung biopsy performed in some cases), it is crucial to reduce the rate of suction (even to zero if needed) until it ceases, and then maintain it for as long as necessary (usually less than $24 \mathrm{~h}$ ). Once the air leakage has stopped, careful progressive suction can be applied again.

\section{Biological aspects of pleurodesis}

In order to achieve a complete symphysis, the pleural surface needs to be irritated, either mechanically with pleural abrasion or through the application of a sclerosing agent. Furthermore, and this is a recently developed concept, there is an increasing body of knowledge about the role of a functionally responsive mesothelium to the sclerosing stimulus.

\section{Choice of the sclerosing agent}

Since 1935, the year in which Bethune [40] reported the application of talc into the pleural space to provoke adhesions, more than 30 agents have been proposed as sclerosants to induce pleurodesis. One of the most detailed reviews of the literature in English about this topic was presented recently by WALKER-RENARD et al. [41]. They concluded that, once parenteral tetracycline production had been discontinued (doxycycline and minocycline are good tetracycline replacements), talc was the most effective and least expensive agent. From the review of these authors and others [11, 12, 42-44], we could summarize as follows.

Tetracycline hydrochloride. Tetracycline has a wide range of efficacy (45-77\%). It requires heavy analgesia, but its main problem is that production of the parenteral form has been discontinued and the remaining stock is decreasing rapidly. Moreover, a relatively high rate of late recurrences has been reported.

Doxycycline. The average effectiveness of doxycyline is $72 \%$ but it often requires repeated doses, sometimes for more than 2 weeks, which is seen as a drawback.

Minocycline. Like doxycycline, minocycline has been proposed as a replacement for tetracycline. An overall success rate of $86 \%$ has been reported in some short series. It can provoke vestibular symptoms when the doses required for pleurodesis are used, and a high rate of haemothorax after application of those high doses has been reported in experimental studies [45].

Bleomycin. Although bleomycin appears to be more effective in clinical practice than in experimental animal studies [46], its main drawbacks are cost and systemic absorption, with risk of significant toxicity. 
Corynebacterium parvum pleurodesis. Almost exclusively used in some European centres, the average effectiveness of this procedure has been reported to be $76 \%$. However, in a randomized study with bleomycin it was effective in only $32 \%$ of cases [47].

Quinacrine. Frequently used in Scandinavia, quinacrine can provoke serious toxicity of the central nervous system, probably due to the high doses that are required [48].

Talc. Although talc has a reported effectiveness of $91 \%$, in most series it has been used via thoracoscopy, which has a long learning curve and, therefore, requires extensive experience.

General anaesthesia or tracheal intubation is not necessary for thoracoscopic talc poudrage, though careful local anaesthesia with parenteral analgesia is mandatory. We have performed more than 300 procedures in the last $15 \mathrm{yrs}$, using the association of local anaesthesia (mepivacaine) and up to $100 \mathrm{mg}$ of parenteral pethidine for analgesia/sedation, with a good overall tolerance and very few complications [39]. At the moment of writing this article, we have had 299 evaluable patients for results of talc poudrage, and have had an overall complete response (defined as absence of significant reaccumulation of the effusion during the whole follow-up, and determined by chest radiography) of $89 \%$. However, when pleural $\mathrm{pH}$ was $>7.30$ we had a success rate of $95 \%$, as compared to a $76 \%$ response in patients with $\mathrm{pH}<7.30$.

When thoracoscopy is not available, many groups are using a "talc slurry" (talcum powder suspended in variable amounts of saline), with an overall reported success of $91 \%$ which is comparable with that of talc insufflation $[44,49]$. However, the studies on talc slurry are smaller than those involving talc poudrage, and we and others [50] believe that there will be some difference in favour of the dry form in the future. Talc is not watersoluble, and in the form of a suspension it may granulate to the dependent part of the pleural space shortly after its instillation. This phenomenon would prevent the sclerosing agent reaching as much mesothelial surface as possible, and, since there is increasing evidence that the role of the mesothelium as a "target" for pleurodesis is crucial (see below), the attempts at symphysis would be expected to fail more frequently.

Complications related to talc are rare, provided that a sterile and asbestos-free form is used. Severe pain is less frequent than with tetracycline, in our experience, and mild fever (probably related to the inflammatory process) is commonly seen for 2-3 days after the procedure. A few major complications have been reported in the literature, but they may be related to excessive dosage and/or other independent factors [51].

Fibrin glue. This agent has been successfully used as a sealant for air leaks in pneumothorax [52], but its use in effusions is more controversial, due to cost and lack of evidence of experimental effectiveness [53]. Moreover, we have recently demonstrated that failure of pleurodesis in malignant effusions is associated with increased pleural fibrinolysis, which could lead to rapid destruction of the fibrin glue applied in malignancy [54].

\section{Role of the mesothelium in pleurodesis}

Until recently, it was assumed that severe damage to the mesothelial layer was necessary to achieve a pleural symphysis. This is true when mechanical pleural abrasion or pleurectomy is performed, but recently there is increasing evidence for a new concept (fig. 2) that the mesothelium itself is the primary initiator of the biological cascade leading to pleurodesis. We already know that production/release of mediators for inflammation and fibrosis by the mesothelial cells themselves are essential to achieve a good pleural symphysis, provided that mechanical conditions (see above) have been accomplished. This fact implies that the sclerosing agent must reach the maximum surface area of normal mesothelium for best results. Thus, when the mesothelial surface is covered by tumour or fibrin, and this circumstance is associated with low glucose and $\mathrm{pH}$ levels, the rate of failure is much higher. This is also the reason why much lower doses of sclerosing agent are required to induce pleurodesis in pneumothorax (in which the mesothelial surface is almost completely preserved) than in malignant effusions.

The cellular mechanisms involved in pleurodesis are not yet fully known, but it seems that, besides mesothelial cells, inflammatory cells recruited from the blood stream (namely neutrophils and mononuclear phagocytes) play an essential role $[55,56]$. There is also some evidence that the superior effectiveness of talc as sclerosing agent may be related to phagocytosis of its particles following instillation into the pleural space $[57,58]$.

The recruitment and proliferation of fibroblasts in the pleural space is obviously essential for the process of pleurodesis, and we now have evidence that both tetracycline and talc stimulate mesothelial cells to produce/release fibroblast growth factor [59, 60].

One of the first phenomena taking place after the sclerosing agent has been instilled is an activation of the pleural coagulation cascade. Agrenius and co-workers $[61,62]$ demonstrated an increase in pleural coagulation and decrease of fibrinolytic activity after the instillation of a sclerosing agent. Since it is assumed that a fibrin mesh formation is a necessary step for fibroblast recruitment (through "haptotaxis" mechanism) and subsequent proliferation into the pleural space [63], we hypothesized that either an impaired fibrin formation or an increased endopleural fibrinolysis would lead to failure of

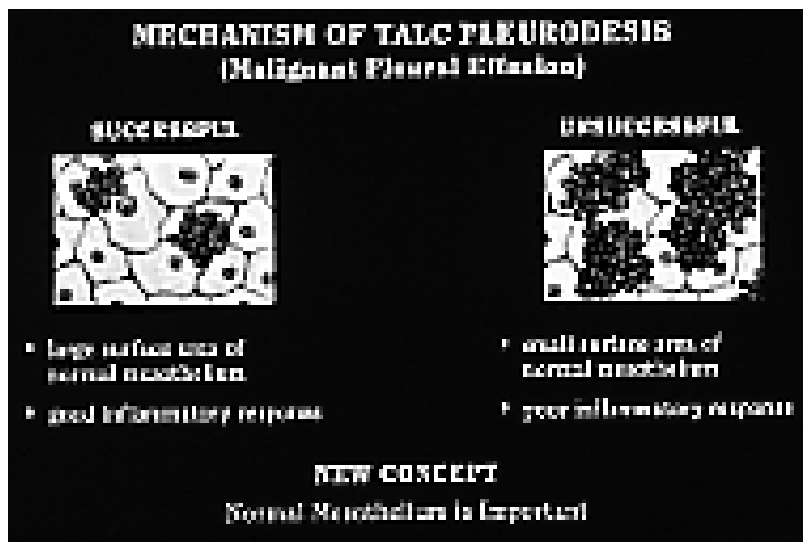

Fig. 2. - New concept about the role of pleural mesothelium in pleurodesis. 


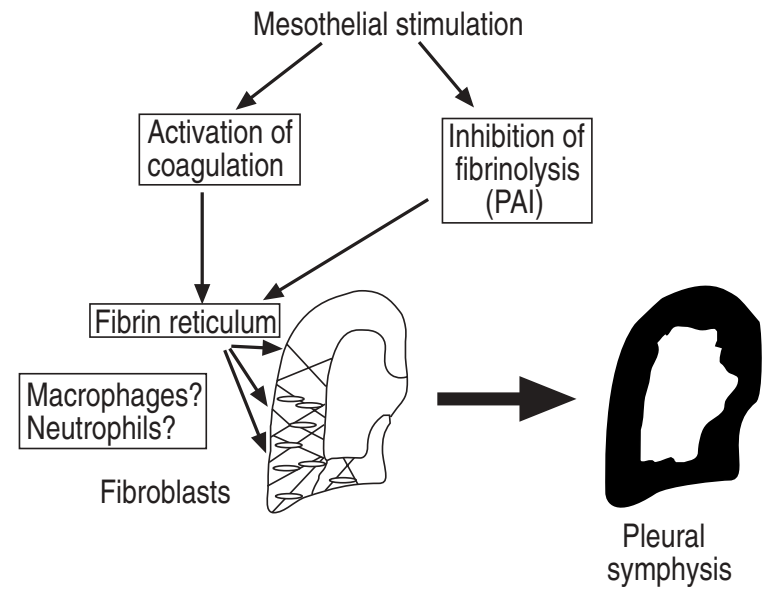

Fig. 3. - Mechanisms involved in the first steps of talc pleurodesis. PAI: plasminogen activator inhibitor.

pleurodesis in malignant effusions (fig. 3). According to this hypothesis, we have recently demonstrated that failure of talc pleurodesis is associated with an increased pleural fibrinolysis [54]. At the present time, we believe that the mesothelium itself regulates the pleural coagulation/fibrinolysis balance and the first steps of the pleural fibrosis process. Furthermore, there is a growing body of knowledge concerning the association of fibrinolytic activity with tumour aggressiveness in other organs. Thus, it seems likely that the strong fibrinolytic activity that was detected in our failed cases of pleurodesis comes, at least in part, from the neoplastic cells in the pleural space.

The cellular and biochemical mechanisms involved in pleurodesis may be specific to the agent used. However, they may all follow a common final pathway leading to activation of the pleural coagulation cascade, the appearance of fibrin networks and the proliferation of fibroblasts. The details of these mechanisms are still unclear and need to be further elaborated. Understanding the pathways involved in pleurodesis should eventually aid in a better understanding of management of patients with pleural disease.

Acknowledgement: The authors wish to thank J. Otter for her secretarial assistance in writing this manuscript.

\section{References}

1. Meyer PC. Metastatic carcinoma of the pleura. Thorax 1966; 21: 427-433.

2. Rodriguez-Panadero F, Borderas Naranjo F, Lopez Mejias J. Pleural metastatic tumours and effusions: frequency and pathogenic mechanisms in a postmortem series. Eur Respir J 1989; 2: 366-369.

3. Reshad K, Inui K, Takeuchi Y, Takahashi Y, Hitomi S. Treatment of malignant pleural effusion. Chest 1985; 88: 393-397.

4. Fentiman IS, Rubens RD, Hayward JL. Control of pleural effusions in patients with breast cancer: a randomized trial. Cancer 1983; 52: 737-739.

5. Light RW, Jenkinson SG, Minh V, George RB. Observations on pleural pressures as fluid is withdrawn during thoracentesis. Am Rev Respir Dis 1980; 121: 799-804.

6. Segado A, Rodriguez-Panadero F, Martin J, Ayerbe R, Fernandez Guerra J, Valenzuela F. Trapped lung, $\mathrm{pH}$ and outcome of talc pleurodesis in malignant pleural effusions. Eur Respir J 1994; 7 (Suppl. 18): 270s.
7. Rodriguez-Panadero F, Sanchez Gil R, Martin Juan J, Castillo Gomez J. Prediction of results of talc pleurodesis in malignant pleural effusions. Am J Respir Crit Care Med 1994; 149: (4, 2): A1103.

8. Petrou M, Kaplan D, Goldstraw P. Management of recurrent malignant pleural effusions: the complementary role of talc pleurodesis and pleuroperitoneal shunting. Cancer 1995; 75: 801-805.

9. Martini N, Bains MS, Beattie EJ. Indications for pleurectomy in malignant effusion. Cancer 1975; 35: 734-738.

10. Waller DA, Morritt GN, Forty J. Video-assisted thoracoscopic pleurectomy in the management of malignant pleural effusion. Chest 1995; 107: 1454-1456.

11. Sanchez-Armengol A, Rodriguez-Panadero F. Survival and talc pleurodesis in metastatic pleural carcinoma, revisited: report on 125 cases. Chest 1993; 104: 1482-1485.

12. Rodriguez-Panadero F, Lopez Mejias J. Low glucose and $\mathrm{pH}$ levels in malignant pleural effusions: diagnostic significance and prognostic value in respect to pleurodesis. Am Rev Respir Dis 1989; 139: 663-667.

13. Sahn SA, Good JT Jr. Pleural fluid $\mathrm{pH}$ in malignant effusions: diagnostic, prognostic and therapeutic implications. Ann Intern Med 1988; 108: 345-349.

14. Minami H, Saka H, Senda K, et al. Small caliber catheter drainage for spontaneous pneumothorax. Am J Med Sci 1992; 404: 345-347.

15. Conces DJ Jr, Tarver RD, Gray WC, Pearcy EA. Treatment of pneumothoraces utilizing small caliber chest tubes. Chest 1988; 94: 55-57.

16. Casola G, van Sonnenberg E, Keightley A, Ho M, Withers C, Lee AS. Pneumothorax: radiologic treatment with small catheters. Radiology 1988; 166: 89-91.

17. Varela G, Arroyo A, Larru E, Diaz-Hellin V, Gamez P. Tratamiento del neumótorax con drenaje fino sin sello de agua (English Abstract). Arch Bronconeumol 1994; 30: 185-187.

18. Almind M, Lange P, Viskum K. Spontaneous pneumothorax: comparison of simple drainage, talc pleurodesis, and tetracycline pleurodesis. Thorax 1989; 44: 627-630.

19. Alfageme I, Moreno L, Huertas C, Vargas A, Hernandez J, Beiztegui A. Spontaneous pneumothorax: long-term results with tetracycline pleurodesis. Chest 1994; 106: 347-350.

20. Donahue DM, Wright CD, Viale G, Mathisen DJ. Resection of pulmonary blebs and pleurodesis for spontaneous pneumothorax. Chest 1993; 104: 1767-1769.

21. Liu H-P, Lin PJ, Hsieh M-J, Chang J-P, Chang C-H. Thoracoscopic surgery as a routine procedure for spontaneous pneumothorax: results from 82 patients. Chest 1995; 107: 559-562.

22. Janssen JP, van Mourik J, Cuesta Valentin M, Sutedja G, Gigengack K, Postmus PE. Treatment of patients with spontaneous pneumothorax during videothoracoscopy. Eur Respir J 1994; 7: 1281-1284.

23. Naunheim KS, Mack MJ, Hazelrigg SR, et al. Safety and efficacy of video-assisted thoracic surgical techniques for the treatment of spontaneous pneumothorax. $J$ Thorac Cardiovasc Surg 1995; 109: 1198-1204.

24. Berger R. Pleurodesis for spontaneous pneumothorax: will the procedure of choice please stand up? Chest 1994; 106: 992-994.

25. Milanez JRC, Vargas FS, Filomeno LTB, Fernandez A, Jatene A, Light RW. Intrapleural talc for the prevention of recurrent pneumothorax. Chest 1994; 106: 1162-1165.

26. Hausmann M, Keller R. Thoracoscopic pleurodesis in spontaneous pneumothorax. Schweiz Med Wschr 1994; 124: 97-104. 
27. Van de Brekel JA, Duurkens VAM, Vanderschueren RGJRA. Pneumothorax: results of thoracoscopy and pleurodesis with talc poudrage and thoracotomy. Chest 1993; 103: 345-347.

28. Harrison LH Jr. In some cases - avoid talc pleurodesis. Chest 1995; 108: 289.

29. Boutin C, Viallat JR, Aelony Y. Thoracoscopy in the diagnosis and treatment of spontaneous pneumothorax. In: Boutin C, Viallat JR, Aelony Y, eds. Practical Thoracoscopy. Berlin/Heidelberg, Springer-Verlag, 1991; pp. 73-81.

30. Kennedy L, Sahn SA. Talc pleurodesis for the treatment of pneumothorax and pleural effusion. Chest 1994; 106: $1215-1222$.

31. Metersky ML, Colt HG, Olson LK, Shanks TG. AIDSrelated spontaneous pneumothorax: risk factors and treatment. Chest 1995; 108: 946-951.

32. Wait MA, Dal Nogare AR. Treatment of AIDS-related spontaneous pneumothorax: a decade of experience. Chest 1994; 106: 693-696.

33. Kimmel RD, Karp MP, Cascone JJ, Zinns JS. Talc pleurodesis during videothoracoscopy for Pneumocystis carinii pneumonia-related pneumothorax: a new technique. Chest 1994; 105: 314-315.

34. Colt HG, Dumon J-F. Development of a disposable spray canister for talc pleurodesis: a preliminary report. Chest 1994; 106: 1776-1780.

35. Noppen M, Dhondt E, Mahler T, Malfroot A, Dab I, Vincken W. Successful management of recurrent pneumothorax in cystic fibrosis by localized apical thoracoscopic talc poudrage. Chest 1994; 106: 262-264.

36. Sudduth C, Sahn SA. Pleurodesis for nonmalignant pleural effusions: recommendations. Chest 1992; 102: $1855-1860$.

37. Vargas FS, Milanez JRC, Filomeno LTB, Fernandez A, Jatene A, Light RW. Intrapleural talc for the prevention of recurrence in benign or undiagnosed pleural effusions. Chest 1994; 106: 1771-1775.

38. Cantó A, González A, Moya J, et al. La pleurodesis con talco en los derrames pleurales masivos y recidivantes de las cirrosis hepáticas (English Abstract). Arch Bronconeumol 1989; 25: 256-258.

39. Rodriguez-Panadero F. Talc pleurodesis for treating malignant pleural effusions. Chest 1995; 108: 1178-1179.

40. Bethune N. Pleural poudrage: a new technique for the deliberate production of pleural adhesions as a preliminary to lobectomy. J Thorac Surg 1935; 4: 251-261.

41. Walker-Renard PB, Vaughan LM, Sahn SA. Chemical pleurodesis for malignant pleural effusions. Ann Intern Med 1994; 120: 56-64.

42. Rivas de Andres JJ, Cantó A, Moya J. Pleurodesis: indicaciones, técnicas y resultados (English Abstract). Arch Bronconeumol 1984; 20: 256-263.

43. Caminero Luna JA. Pleurodesis. Med Clin (Barc) 1993; 101: 212-215.

44. Kennedy L, Sahn SA. Talc pleurodesis for the treatment of pneumothorax and pleural effusion. Chest 1994; 106: $1215-1222$.

45. Light RW, Wang NS, Sassoon CSH, Gruer SE, Vargas FS. Comparison of the effectiveness of tetracycline and minocycline as pleural sclerosing agent in rabbits. Chest 1994; 106: 577-582.

46. Vargas FS, Wang N-S, Lee HM, Gruer SE, Sassoon CSH, Light RW. Effectiveness of bleomycin in comparison to tetracycline as pleural sclerosing agent in rabbits. Chest 1993; 104: 1582-1584.

47. Ostrowsky MJ, Priestman TJ, Houston RF, Martin WM. A randomized trial of intracavitary bleomycin and
Corynebacterium parvum in the control of malignant pleural effusions. Radiother Oncol 1989; 14: 19-26.

48. Bjorkman S, Elisson LO, Gabrielson J. Pharmacokinetics of quinacrine after intrapleural instillation in rabbits and man. J Pharm Pharmacol 1989; 41: 160-163.

49. Kennedy L, Rusch VW, Strange C, Ginsberg R, Sahn SA. Pleurodesis using talc slurry. Chest 1994; 106: 342-346.

50. Aelony Y. Talc pleurodesis: talc slurry $v s$ talc poudrage. Chest 1995; 108: 289.

51. Loddenkemper R, Boutin C. Thoracoscopy: present diagnostic and therapeutic indications. Eur Respir J 1993; 6: $1544-1555$.

52. Hauck H, Bull PG, Pridun N. Complicated pneumothorax: short and long-term results of endoscopic fibrin pleurodesis. World J Surg 1991; 15: 146-150.

53. Seitz B, Delpierre S, Choux R, Lama A, Boutin C. Etude experimentale des effects pleuraux de la pulvérisation, sous contrôle thoracoscopique, d'une colle de fibrine (Tissucol). Rev Mal Respir 1989; 6: 537-542.

54. Rodriguez-Panadero F, Segado A, Martin Juan J, Ayerbe R, Torres Garcia I, Castillo J. Failure of talc pleurodesis is associated with increased pleural fibrinolysis. $\mathrm{Am}$ J Respir Crit Care Med 1995; 151: 785-790.

55. Antony VB, Godbey SW, Kunkel SL, et al. Recruitment of inflammatory cells to the pleural space: chemotactic cytokines, IL-8, and monocyte chemotactic peptide-1 in human pleural fluids. J Immunol 1993; 151: 72167223.

56. Antony VB, Hott JW, Kunkel SL, Godbey SW, Burdick MD, Strieter RM. Pleural mesothelial cell expression of C-C (monocyte chemotactic peptide) and C-X-C (interleukin 8) chemokines. Am J Respir Cell Mol Biol 1995; 12: $581-588$.

57. Hartman DL, Antony VB, Hott JW, Godbey SW, Yu L, Rodriguez-Panadero F. Thoracoscopic talc insufflation increases pleural fluid IL-8 levels in patients with malignant pleural effusions. Am J Respir Crit Care Med 1994; Suppl. 149 (2, 2): A974.

58. Hartman DL, Harper-Allen PJ, Godbey SW, Hott JW, Yu L, Antony VB. Phagocytosis of talc particles by human pleural mesothelial cells (HPMC) correlates with IL-8 production. Am J Respir Crit Care Med 1994; Suppl. 148 (2, 2): A845.

59. Antony VB, Rothfuss KJ, Godbey SW, Sparks JA, Hott JW. Mechanism of tetracycline hydrochloride-induced pleurodesis: tetracycline hydrochloride-stimulated mesothelial cells produce a growth factor-like activity for fibroblasts. Am Rev Respir Dis 1992; 146: 1009-1013.

60. Godbey SW, Holm KA, Yu L, Hott JW, RodriguezPanadero F, Antony VB. Role of mesothelial cells in pleural fibrosis following successful talc poudrage: identification of basic fibroblast growth factor (FGF-2) in pleural fluids. Am J Respir Crit Care Med 1995; Suppl. 151 (2, 2): A353.

61. Agrenius V, Chmielewska J, Widström O, Blombäck M. Increased coagulation activity of the pleura after tube drainage and quinacrine instillation in malignant pleural effusion. Eur Respir J 1991; 4: 1135-1139.

62. Agrenius V, Chmielewska J, Widström O, Blombäck M. Pleural fibrinolytic activity is decreased in inflammation as demonstrated in quinacrine pleurodesis treatment of malignant pleural effusion. Am Rev Respir Dis 1989; 140: 1381-1385.

63. Dryzer SR, Joseph J, Baumann M, Birmingham K, Sahn SA, Strange C. Early inflammatory response of minocycline and tetracycline on the rabbit pleura. Chest 1993; 104: $1585-1588$. 